\title{
Segregated Planktonic and Bottom-Dwelling Archaeal Communities in High-Temperature Acidic/Sulfuric Ponds of the Tatun Volcano Group, Northern Taiwan
}

\author{
Ting-Wen Cheng ${ }^{1}$, Pei-Ling Wang ${ }^{2}$, Sheng-Rong Song ${ }^{1}$, and Li-Hung Lin ${ }^{1, *}$ \\ ${ }^{1}$ Department of Geosciences, National Taiwan University, Taipei, Taiwan \\ ${ }^{2}$ Institute of Oceanography, National Taiwan University, Taipei, Taiwan
}

Received 29 November 2012, accepted 11 January 2013

\begin{abstract}
Geothermal environments are characterized by dynamic redox and temperature fluctuations inherited from the exposure of deeply-sourced, hot, reducing fluids to low-temperature, oxidizing ambient environments. To investigate whether microbial assemblages shifted in response to the changes of a redox state within acidic hot ponds, we collected three paired water and sediment samples from the Tatun Volcano Group, assessed metabolic roles of community members, and correlated their functional capabilities with geochemical factors along depth. Molecular analyses revealed that Sulfolobus spp., Acidianus spp. and Vulcanisaeta spp. capable of respiring elemental sulfur under oxic and/or low-oxygen conditions were the major archaeal members in planktonic communities. In contrast, obligate anaerobic Caldisphaera spp. dominated over others in bottomdwelling communities. Bacteria were only detected in one locality wherein the majority was affiliated with microaerophilic Hydrogenobaculum spp. Cluster analyses indicated that archaeal communities associated with sediments tended to cluster together and branch off those with water. In addition, the quantities of dissolved oxygen within the water column were substantially less than those in equilibrium with atmospheric oxygen, indicating a net oxygen consumption most likely catalyzed by microbial processes. These lines of evidence suggest that the segregation of planktonic from bottom-dwelling archaeal assemblages could be accounted for by the oxygen affinities inherited in individual archaeal members. Community assemblages in geothermal ecosystems would be often underrepresented without cautious sampling of both water and sediments.
\end{abstract}

Key words: Tatun Volcano Group, Hot spring, Archaeal community, Oxygen affinity

Citation: Cheng, T. W., P. L. Wang, S. R. Song, and L. H. Lin, 2013: Segregated planktonic and bottom-dwelling archaeal communities in high-temperature acidic/sulfuric ponds of the Tatun Volcano Group, northern Taiwan. Terr. Atmos. Ocean. Sci., 24, 345-356, doi: 10.3319/TAO.2013.01.11.01(TT)

\section{INTRODUCTION}

One distinctive feature in geothermal systems is that deeply-sourced, hot, reducing fluids discharged along fractures interact with cool, oxidized environments near the Earth's surface, creating steep redox and temperature gradients. Thermophilic microbes exploit such chemical disequilibria to harvest metabolic energy in accordance with their intrinsic physiological capabilities (Meyer-Dombard et al. 2005; Shock et al. 2005; D'Imperio et al. 2008). Microbially-mediated processes would have to compete with abiotic oxidation for reduced constituents released from the source fluid. The factors that control the distribution, function and

\footnotetext{
* Corresponding author

E-mail:lhlin@ntu.edu.tw
}

diversity of thermophilic microbial communities on various scales remain ambiguous.

Although great effort has been dedicated to the isolation of novel thermophilic microorganisms and exploration of genetic diversity, the overall community function is not well constrained. This is due to the fact that the inference of potential metabolism based on the sequence identity is often hindered by the great genetic distance from the known cultures (D'Imperio et al. 2008; Perevalova et al. 2008). Instead, one approach commonly adopted for assigning potential functions to a large number of environmental sequences is the establishment of the correlation between geochemical parameters and community assemblages along a transect or depth profile. For example, Macur et al. (2004) described the variation in community assemblages along a re-directed 
stream flow both spatially and temporally in the Succession Spring of Yellowstone National Park (YNP), USA. Community structures shifted with a successive increase in oxidative state and decreasing temperature downstream the flow. Costa et al. (2009) investigated four hot springs supplied by a point-sourced fluid experiencing different groundwater circulations in the Great Basin, USA. Their study indicated that microbial community compositions were mainly controlled by the water residence time. As most water bodies that could link to the interactions between subsurface and surface processes in the volcanically influenced area are restrained within individual hot ponds, little attention has been paid in investigating how the transition of a redox state driven by atmospheric oxygen controls the distribution of functionality and community assemblage in water columns and bottom sediments.

To better address how thermoacidophilic communities respond to the flux of atmospheric oxygen, we collected samples from water columns and bottom sediments of sulfuric hot ponds in northern Taiwan for analyses of the geochemistry and community structure. These ponds were chosen because the water temperatures exceeded $65^{\circ} \mathrm{C}$ and the $\mathrm{pH}$ was less than 3 , so the potential for oxygen produced by thermophilic phototrophs was minimized (Cox et al. 2011). The objectives of this work were to (i) compare the assemblages of planktonic and bottom-dwelling communities; (ii) quantify the geochemical gradients in the water column; and, (iii) provide the semi-quantitative estimates to constrain the influence of atmospheric oxygen on the abiotic and biotic oxidation of reduced compounds. Our results indicated that aerobic and anaerobic archaeal communities were segregated into different niches in accordance with their physiological characteristics and limits.

\section{MATERIALS AND METHODS}

\subsection{Geological Background and Study Sites}

Samples were collected from the Tatun Volcano Group (TVG) in northern Taiwan (Fig. 1) where the majority of rocks are andesite with a minor fraction of basalt (Chen and $\mathrm{Wu}$ 1971). Geochemical analyses indicate that these volcanic rocks were derived from the post-collisional volcanism related to the subduction-collision between the Philippine Sea and Eurasian Plates starting from 5 million years ago (Wang et al. 1999). At least three major eruptions are identified with the latest and greatest occurring 20000 years ago (Song et al. 2000). The TVG is cross-cut by two major faults, the Chin-Shan and the Kan-Chiao faults, trending northeast to southwest (Fig. 1). Geothermal features, including fumaroles, boiling ponds, and springs are distributed on the hanging wall side of the Chin-Shan fault near the fault boundary.

The samples were collected from three sulfuric hot ponds in the TVG (Fig. 1). The study sites include the Huang-Shan area (designated as "HS"; $25^{\circ} 8^{\prime} 38^{\prime \prime N}$; $\left.121^{\circ} 31^{\prime} 29^{\prime \prime} \mathrm{E}\right)$ and the Liu-Huang valley (designated as "LH"; $\left.25^{\circ} 11^{\prime} 10^{\prime \prime} \mathrm{N} ; 121^{\circ} 36^{\prime} 48^{\prime \prime} \mathrm{E}\right)$ where the geothermal activity is among the greatest in the TVG. Both the HS and LH areas are typical phreatic craters characterized by steaming fumaroles that discharge $\mathrm{CO}_{2}, \mathrm{H}_{2} \mathrm{~S}$, and $\mathrm{SO}_{2}$ as the main gas phases (Lee et al. 2005). Two naturally occurring ponds (HSO3 and HSO4) were selected in the HS area with area sizes of $\sim 40 \mathrm{~m}^{2}$ for $\mathrm{HSO} 03$ and $\sim 4 \mathrm{~m}^{2}$ for HSO4. The LH area received much more anthropogenic disturbance. Only one pond (LH02) with an area size of $\sim 10 \mathrm{~m}^{2}$ was chosen for sampling. The LH02 pond was supplied episodically with water from the adjacent creek and drained for downstream recreational purposes. All of the ponds investigated have multiple inputs of fumarolic gases visualized from the bubbling on the water surface. Thick, yellowish sediments were observed accumulating on the pond floor. X-ray diffraction analyses indicated that these yellowish particles were composed of elemental sulfur. The water level and temperature fluctuated, depending on the local precipitation and the degree of mixing with creek water. Overall, geological characteristics in these two areas are very similar despite a separation of approximately $20 \mathrm{~km}$.

\subsection{Sampling and Field Measurements}

The first sampling was carried out in 2006. Temperature, $\mathrm{pH}, \mathrm{ORP}$, and conductivity were recorded on site with a handheld meter (WTW Multi 340i, Weilheim, Germany). Water samples were collected from the top $15 \mathrm{~cm}$ using a peristaltic pump equipped with 5-meter long Masterflex tubing (Cole-Parmer, Vernon Hills, IL, USA) attached to an aluminum pole. The tubing was flushed with the pond water for $2 \mathrm{~min}$ in order to remove air trapped within the tubing. The water samples were immediately filtered through a $0.22 \mu \mathrm{m}$-pore-sized cellulose membrane (Millipore, Billerica, MA, USA). While the filtrates were collected for analyses of aqueous chemistry, the filters were preserved for DNA analysis. Samples for aqueous chemistry were collected with or without the addition of preservatives (1\% nitric acid for cations, $0.1 \%$ sulfuric acid for ammonium, $0.1 \mathrm{mM}$ zinc acetate for sulfide, and no additive for anions). The filters for DNA analysis represented a filtrate volume of $0.9-5.1 \mathrm{~L}$ water, depending on the turbidity, and were placed into sterile $15 \mathrm{~mL}$ centrifuge tubes. Top sediments in the pond bottom for DNA analysis were collected with a sterilized polypropylene cup and placed into $50 \mathrm{~mL}$ centrifuge tubes. The sample containers and sampling gears were sterilized and isolated from exposure to the atmosphere prior to each trip. All samples were shipped back to the laboratory within $2 \mathrm{~h}$ for permanent storage in a $4^{\circ} \mathrm{C}$ refrigerator (for aqueous and gas samples) and a $-80^{\circ} \mathrm{C}$ freezer (for DNA samples).

To investigate the vertical variation in aqueous and gas geochemistry within the water column, subsequent sam- 


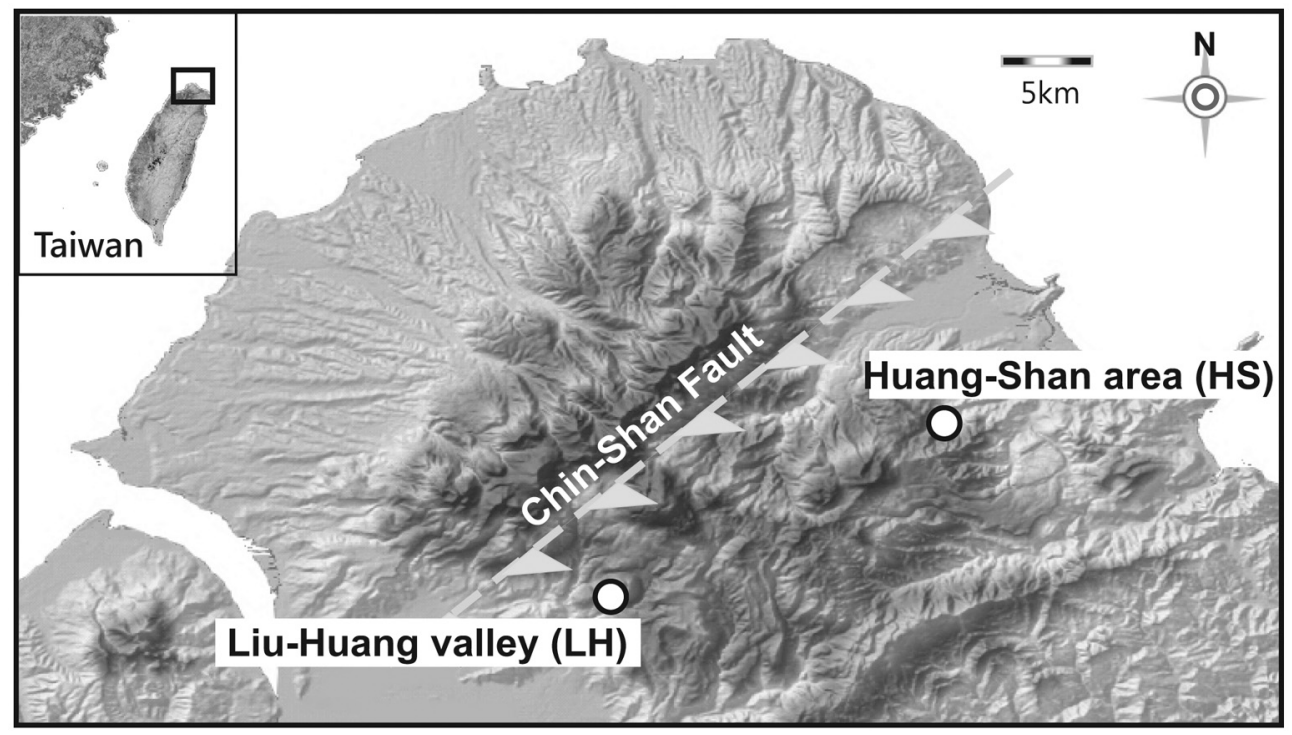

Fig. 1. Topographic map of the TVG with sampling sites marked in open circles.

pling was performed in 2007 for only LH02 and HSO3 due to the unexpected drain-out of the HS04 water for recreational purposes. In order to acquire samples from different depths, the depth of water-sediment interface was first measured by immersing an aluminum pole marked in centimeters into the water column. Once the depth of water column was determined, another aluminum pole was tied perpendicularly to the first one and sustained on the edge of the pond. Three depth intervals representing the top, middle and bottom fractions of the water column were chosen for sampling. Tubing was attached along the poles to reach the designated depth at which water was withdrawn by a peristaltic pump at a rate of $\sim 100 \mathrm{~mL} \mathrm{~min}^{-1}$ for several minutes first in order to remove air trapped within the tubing and subsequently diverted into designated containers for aqueous and gas geochemistry. Aqueous samples were preserved as described previously. Samples for dissolved gases were collected by diverting water into the pre-evacuated serum bottles $(160 \mathrm{~mL})$ until the water level within the bottles remained constant. Pore water and dissolved gases associated with sediments from the pond bottom could not be obtained because high particle loads prevent the direct suction using the peristaltic pump.

\subsection{Aqueous and Gas Geochemistry}

Cations were measured on an inductively coupled plasma-atomic emission spectrometer (ICP-AES) (Horiba Jobin Yvon, Edison, NJ, USA). Anions were determined using an ion chromatograph (Metrohm, Herisau, Switzerland). Ammonia was determined via a colorimetric method (Clesceri et al. 1998). Dissolved sulfide was measured using the meth- ylene blue method (Cline 1969). Dissolved organic carbon (DOC) was measured from acidified samples as $\mathrm{CO}_{2}$ was generated by persulfate oxidation using an infrared detector (1010TOC, O-I-Analytical, College Station, TX, USA). Analyses of dissolved gases were carried out on a 6890N gas chromatograph (Agilent Technology, Santa Clara, CA, USA) equipped with a thermal conductivity detector (for $\mathrm{H}_{2}$ and $\mathrm{O}_{2}$ ), a methanizer (for conversion of $\mathrm{CO}_{2}$ to $\mathrm{CH}_{4}$ ), and a flame ionization detector (for hydrocarbons). Dissolved $\mathrm{CO}_{2}$ was measured from acidified gas samples by converting $\mathrm{CO}_{2}$ to $\mathrm{CH}_{4}$ through the methanizer followed by the detection on a flame ionization detector. The concentrations of dissolved gases were derived from the molar abundances, the volume ratio of headspace to aqueous phase in a serum bottle, and the Henry's law constants (Andrews and Wilson 1987). The detection limits were $0.1 \mathrm{ppm}$ for anions and cations, $10 \mathrm{ppmv}$ for hydrogen and hydrocarbon, and $100 \mathrm{ppmv}$ for $\mathrm{O}_{2}$. The analytical uncertainties for aqueous chemistry and gas measurements were \pm 1 and $\pm 5 \%$, respectively.

\subsection{DNA Extraction, Cloning, Screening, and Sequencing}

Genomic DNA was extracted directly from $10 \mathrm{~g}$ of sediments from each pond and filters representing a total filtrate volume of $0.9,2.8$, and 5.1 L for HSO3, HSO4, and LH02, respectively. The Ultraclean Mega Soil DNA Isolation Kit (MO BIO Labs, Solana Beach, CA, USA) was used following the manufacturer's instructions with the exception that the elution volume was adjusted to $2 \mathrm{~mL}$. The extracts were further condensed through spin columns (MO BIO Labs, Solana Beach, CA, USA) to $140 \mu \mathrm{L}$. Nearly full length 16S rRNA gene fragments were amplified by 
polymerase chain reaction (PCR) on a Robocycler (Stratagene, La Jolla, CA, USA) using a bacteria-specific primer B27F and a universal primer U1492R (Lane 1991) for bacteria, and an archaea-specific primer A20F (DeLong et al. 1999) and a universal primer U1406R (Eder et al. 1999) for archaea.

The PCR mixture (a total of $25 \mu \mathrm{L}$ ) contained 0.5 unit of the Ex Taq (Takara, Otsu, Shiga, JP), 1X Taq buffer with $2.5 \mathrm{mM} \mathrm{Mg}^{2+}, 0.5 \mathrm{mM}$ of each primer, $0.2 \mathrm{mM}$ of each deoxynucleotide, and $1 \mu \mathrm{L}$ of template. The temperature protocol for PCR amplification targeting bacteria included an initial denaturation at $94^{\circ} \mathrm{C}$ for $2 \mathrm{~min}$, followed by 30 cycles of $30 \mathrm{~s}$ denaturation at $94^{\circ} \mathrm{C}, 45 \mathrm{~s}$ annealing at $54^{\circ} \mathrm{C}$, and $1 \mathrm{~min}$ extension at $72^{\circ} \mathrm{C}$, and a final extension at $72^{\circ} \mathrm{C}$ for $7 \mathrm{~min}$. For archaea, the temperature scheme was the same as that for bacteria except that the annealing temperature was set at $60^{\circ} \mathrm{C}$. The PCR product was further purified with a StrataPrep ${ }^{\circledR}$ PCR purification kit (Stratagene, La Jolla, CA, USA) following the manufacturer's protocol and resuspended in $50 \mu \mathrm{L}$ of elution buffer.

The cloning of purified PCR products was carried out using a TOPO TA cloning kit (Invitrogen, Carlsbad, CA, USA) according to the manufacturer's instructions. For each clone library, at least 20 colonies containing positive inserts were screened by digestion with the restriction enzyme RsaI for archaea or HaeIII for bacteria. The digested fragments were separated on a $2 \%$ agarose gel by electrophoresis. The patterns were grouped by a unique restriction fragment length polymorphism (RFLP) type. To check whether colony sequences belonging to a specific phylotype were identical, at least two colonies, unless only one colony standing for a unique RFLP pattern, were randomly chosen and sequenced on an ABI 3730 sequencer (Applied Biosystems, Foster, CA, USA). Sequence-editing and contig-assembling of the partial forward and reverse fragments were performed using a SEQUENCHER 4.7 (Gene Codes, Ann Arbor, MI, USA). All sequences were checked for potential chimera formation using the Chimera_Check program available from the Ribosomal Database Project (RDP-II) (Maidak et al. 2001) and Pintail (Ashelford et al. 2005). Potential chimeras were excluded from further analyses.

Sequences representing each phylotype were compared with those in the GenBank, and nearest BLAST results (including both nearest culture representatives and uncultured sequences) were used as reference sequences for phylogenetic analyses. Sequence alignment was performed on an online multiple sequence alignment tool - Greengenes via NAST algorithm (DeSantis et al. 2006) and checked manually on MEGA4 (Tamura et al. 2007). Phylogenetic analysis of the aligned sequences was performed based on the Neighbor-Joining method (Saitou and Nei 1987) on MEGA4. The evolution distance was computed using the Maximum Composite Likelihood method (Tamura et al. 2004) with 1000 replicates for bootstrap analysis.

\subsection{Nucleotide Sequence Accession Numbers}

Sequences of $16 \mathrm{~S}$ rRNA genes from water and sediment samples have been deposited in the GenBank under accession numbers from FJ797310 to FJ797344.

\section{RESULTS}

\subsection{Physical and Chemical Characteristics of Fluids}

Field measurements in 2006 yielded fluid temperatures at $82.5,80.7$, and $67.7^{\circ} \mathrm{C}$ for HSO3, HSO4 and LHO2, respectively. All pond fluids were extremely acidic with a $\mathrm{pH}$ ranging between 0.8 and 2.8 (Table 1). Redox potentials of LH02, HSO3 and HSO4 fluids were $-150,-75$, and $-35 \mathrm{mV}$, respectively. Conductivities were high in HS (2420 and $4320 \mu \mathrm{S} \mathrm{cm}^{-1}$ for HS03 and HSO4, respectively) but much lower in LH02 $\left(779 \mu \mathrm{S} \mathrm{cm}^{-1}\right)$. The variation in conductivity was controlled by the most abundant anion, sulfate, which reached a level above $16 \mathrm{mM}$ in HS and $3 \mathrm{mM}$ in LH02. Of the other minor anions, chloride concentrations ranged from 0.76 to $1.43 \mathrm{mM}$ and nitrate concentrations varied from below the detection limit to $122 \mu \mathrm{M}$ (Table 1). Colorimetric measurements yielded $38-816 \mu \mathrm{M}$ of dissolved sulfide. Major cations were generally low with calcium being the most abundant $(1.29,3.82$, and $2.24 \mathrm{mM}$ for LHO2, HS03, and HS04, respectively). Total iron concentrations varied widely from $92.3 \mu \mathrm{M}$ in LH02 to $1.30 \mathrm{mM}$ in HS03, with at least $90 \%$ of the total iron composed of ferrous iron. Dissolved manganese exhibited a variation similar to iron. Detection of ammonium turned out to be false due to the interference of elevated iron on the color development. DOC concentrations varied from 103 to $446 \mu \mathrm{M}$.

Physical and chemical measurements revealed that temperature, redox potential, and $\mathrm{pH}$ did not vary significantly with depth in HSO3 and LH02 (Table 2). Chloride and sulfate were depleted in the top layer of LH02 when compared with those in the middle and bottom layers, but remained at nearly a constant level in HS03. Dissolved sulfide increased from $166 \mu \mathrm{M}$ at $5 \mathrm{~cm}$ to $205 \mu \mathrm{M}$ at $115 \mathrm{~cm}$ in $\mathrm{HSO3}$, and from $82.5 \mu \mathrm{M}$ at $5 \mathrm{~cm}$ to $100 \mu \mathrm{M}$ at $50 \mathrm{~cm}$ in LH02. Dissolved oxygen fluctuated between 29 and $34 \mu \mathrm{M}$ in HS03, whereas a decrease from $\sim 35 \mu \mathrm{M}$ at $5 \mathrm{~cm}$ to $\sim 25 \mu \mathrm{M}$ at $60 \mathrm{~cm}$ occurred in LH02. Dissolved oxygen concentrations were much less than air-saturated equilibrium concentrations (Table 2). Other dissolved gases were only measured for the middle depth in both ponds. Carbon dioxide appeared to be the most abundant species at concentrations of 3980 and $1014 \mu \mathrm{M}$ for HSO3 and LH02, respectively.

\subsection{Compositions of Archaeal and Bacterial Communities}

PCR-amplification yielded archaeal amplicons for all collected samples. Bacteria were, however, only detected in LH02. Screening and sequencing of archaeal and bacterial 
Table 1. Geochemical and physical characteristics of pond water.

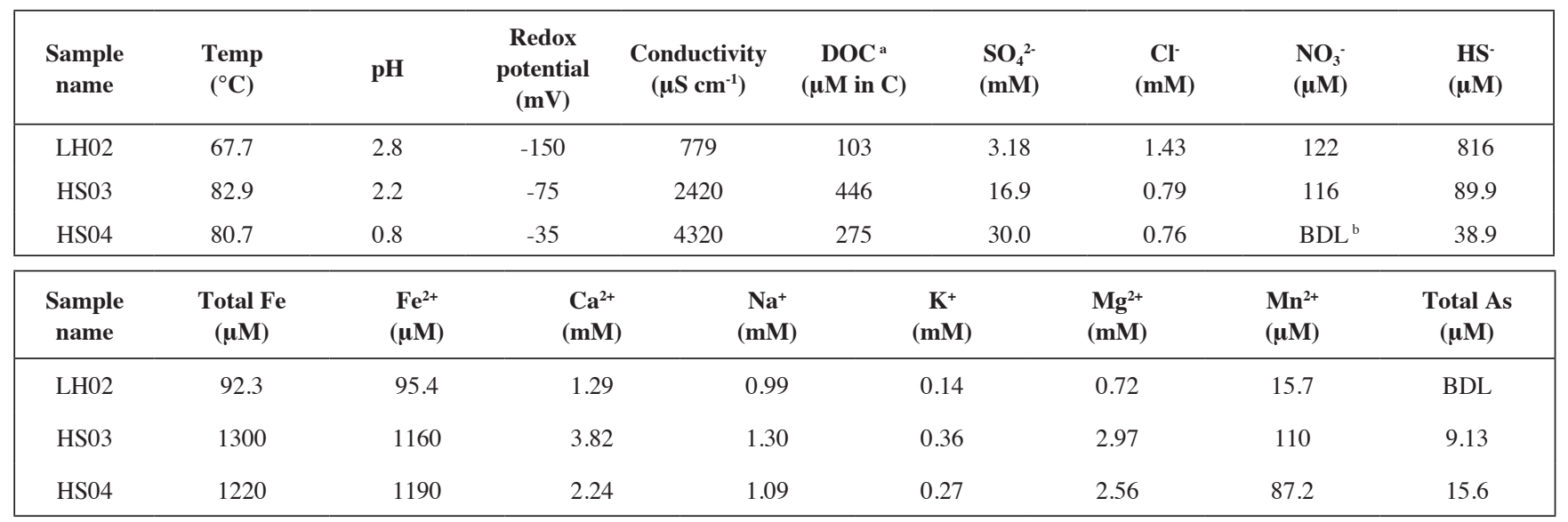

a DOC: Dissolved organic carbon.

b BDL: Below detection limit.

Table 2. Geochemical and physical characteristics along profile in LH02 and HSO3.

\begin{tabular}{|c|c|c|c|c|c|c|c|c|c|}
\hline $\begin{array}{l}\text { Depth below air-water } \\
\text { interface }(\mathbf{c m})\end{array}$ & $\begin{array}{r}\text { Temp } \\
\left({ }^{\circ} \mathrm{C}\right)\end{array}$ & pH & $\begin{array}{l}\mathrm{SO}_{4}^{2-} \\
(\mathrm{mM})\end{array}$ & $\begin{array}{c}\mathbf{H S}^{-} \\
(\mu \mathrm{M})\end{array}$ & $\begin{array}{c}\mathrm{Cl}^{-} \\
(\mu \mathrm{M})\end{array}$ & $\begin{array}{l}\mathrm{NO}_{3}^{-} \\
(\mu \mathrm{M})\end{array}$ & $\begin{array}{c}\mathbf{F e}^{2+} \\
(\mu \mathrm{M})\end{array}$ & $\begin{array}{c}\mathbf{O}_{2} \\
(\boldsymbol{\mu M})\end{array}$ & $\begin{array}{r}\text { Eq. } \mathrm{O}_{2} \\
(\mu \mathrm{M})^{\mathrm{c}}\end{array}$ \\
\hline \multicolumn{10}{|l|}{$\mathrm{LHO}^{\mathrm{a}}$} \\
\hline $5-10$ & 89.0 & 2.9 & 2.53 & 82.5 & 1000 & 39.0 & 163 & 35.3 & 112 \\
\hline $30-40^{d}$ & 89.0 & 2.8 & 3.25 & 83.4 & 1270 & 37.4 & 159 & 34.2 & 112 \\
\hline $50-60$ & 88.8 & 2.9 & 3.27 & 100 & 1260 & 37.0 & 161 & 25.8 & 112 \\
\hline \multicolumn{10}{|l|}{$\mathrm{HS} 3^{\mathrm{b}}$} \\
\hline 5 & 63.6 & 2.9 & 3.08 & 166 & 216 & $\mathrm{BDL}^{\mathrm{e}}$ & 242 & 29.5 & 147 \\
\hline $60^{d}$ & $\mathrm{NA}^{\mathrm{e}}$ & 2.9 & 3.17 & 200 & 228 & $\mathrm{BDL}^{\mathrm{e}}$ & 237 & 33.7 & 143 \\
\hline 115 & 66.5 & 2.8 & 3.17 & 205 & 212 & $\mathrm{BDL}^{\mathrm{e}}$ & 233 & 28.9 & 141 \\
\hline
\end{tabular}

a Aqueous and gas samples from LHO2 were collected on 08/16/07 and 10/23/07, respectively.

b Aqueous and gas samples of HSO3 were collected on 09/07/07. Human-caused drainage of adjacent creek water into HSO3 in 2007 resulted in the lowering of temperature and abundance of major cations and anions.

c Equilibrium $\mathrm{O}_{2}$ : Air-saturated contents of dissolved oxygen were calculated using the Henry's Law constant at the in situ temperatures $\left(65^{\circ} \mathrm{C}\right.$ for the middle depth in HSO3).

$d$ Gas compositions at $30-40 \mathrm{~cm}$ in LHO2: $0.55 \mu \mathrm{M}$ of $\mathrm{H}_{2}, 1014 \mu \mathrm{M}$ of $\mathrm{CO}_{2}$ and $0.05 \mu \mathrm{M}$ of $\mathrm{CH}_{4}$; at $60 \mathrm{~cm}$ in $\mathrm{HSO}: 0.83 \mu \mathrm{M}$ of $\mathrm{H}_{2}, 3980 \mu \mathrm{M}$ of $\mathrm{CO}_{2}$ and $0.67 \mu \mathrm{M}$ of $\mathrm{CH}_{4}$.

e BDL: Below detection limit; NA: Not available.

clone libraries revealed microbial communities with relatively simple structures. A total of 12 phylotypes were identified from the LH02 planktonic archaeal library, whereas less than 6 phylotypes were obtained from the other five archaeal libraries (Table 3). For comparison, only one and three bacterial phylotypes were recovered from the LH02 water and sediment samples, respectively.

A significant proportion of planktonic archaeal members were affiliated with the Order Sulfolobales (Fig. 2 and Table 3). Sequences of $37.5 \%$ clones in HS03 were affiliated with Sulfolobus tokodaii or Sulfurisphaera ohwakuensis (both shared 91 - 97\% identity) isolated from acidic springs in Japan, $94.6 \%$ in HS04 with Sulfolobus metallicus from Icelandic solfataric fields, and 2.7, 5.4, and $21.6 \%$ in LHO2 with S. metallicus, S. tokodaii and Acidianus infernus, respectively (Table 3) (Segerer et al. 1986; Huber and Stetter 1991; Kurosawa et al. 1998; Suzuki et al. 2002). Sequences of other archaeal planktonic members were related to either Vulcanisaeta distributa isolated from several geothermal springs in eastern Japan (62.5\% in HS03) or Caldisphaera lagunensis from a hot pond in the Philippines (4.6\% in HSO4 and $10.8 \%$ in LH02) (Itoh et al. 2002; Itoh et al. 2003). A number of archaeal sequences could not be classified into any known lineage possessing culture representatives, and consisted of 3.6 and $59.5 \%$ of the planktonic communities in HSO4 and LH02, respectively (Fig. 2 and Table 3). These uncultured sequences could be further grouped into 9 phylotypes. Sequences of two phylotypes (A08 and A09) 


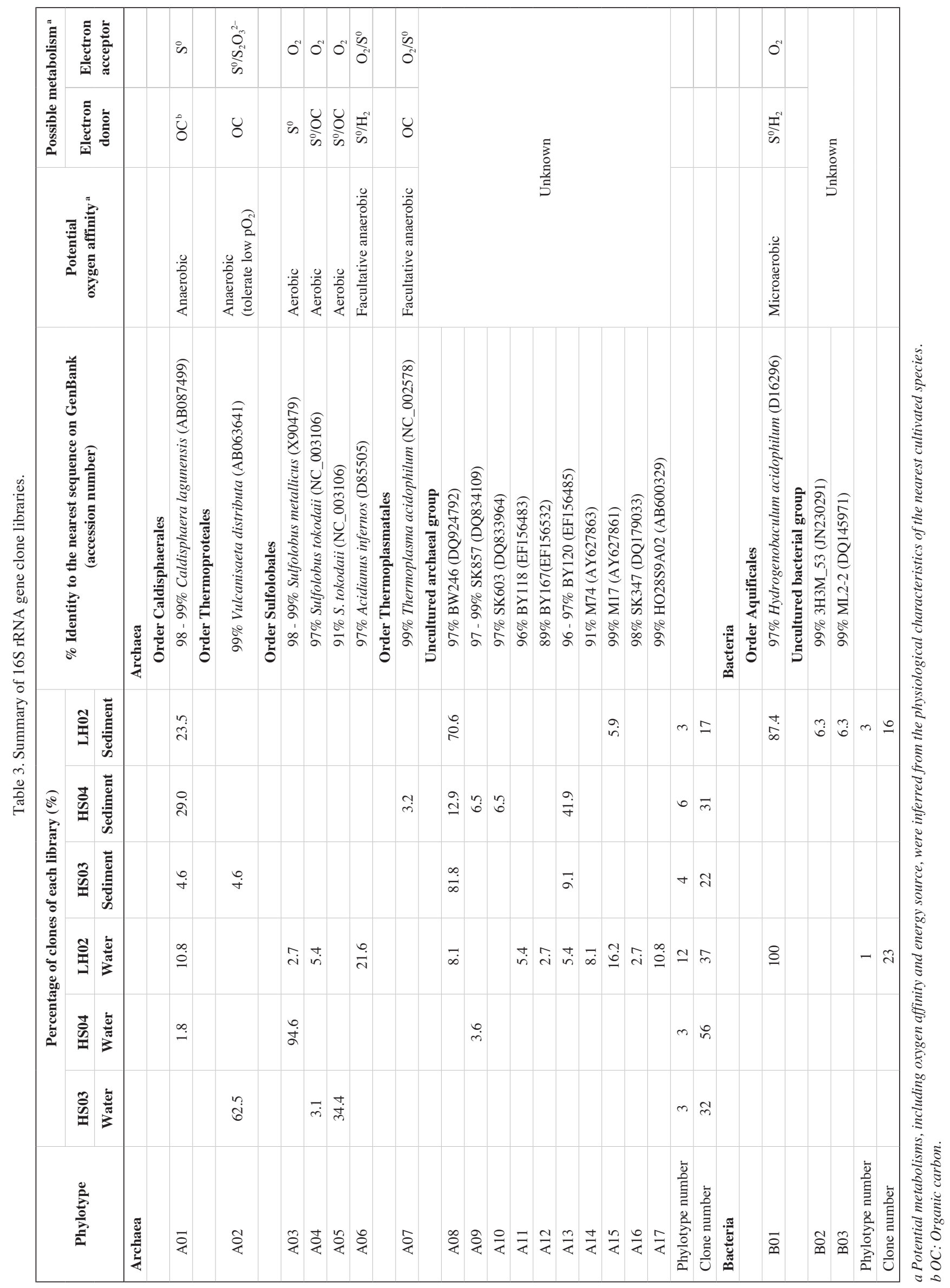




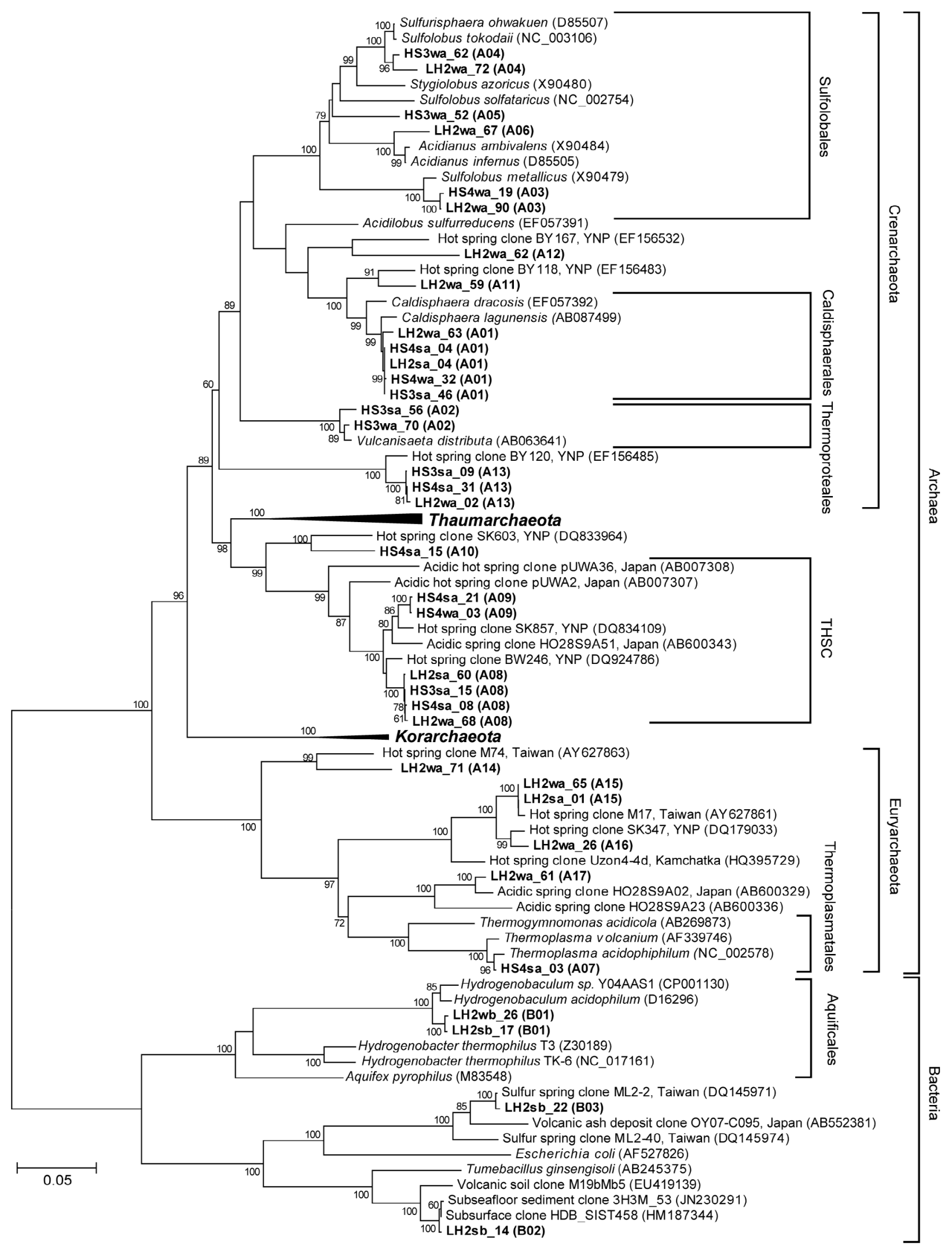

Fig. 2. Phylogenetic tree for archaeal and bacterial 16S rRNA gene sequences obtained from LH02, HSO3 and HS04. The tree was constructed using the Neighbor-Joining method with sequences in lengths of at least $1200 \mathrm{bps}$. Bootstrap values with 1000 replicates are shown next to the branch nodes $(<60 \%$ are not shown). Scale bar represents $5 \%$ evolutionary distance. The sequences obtained in this study are highlighted by clone names in boldface that constitute sample site (HS3, HS4 and LH2), sample type ("w" for water and "s" for sediment) and primer set ("a" for archaea and "b" for bacteria), followed by phylotypes in parentheses. THSC, terrestrial hot spring Crenarchaeota; YNP, Yellowstone National Park (USA). 
were related to the Terrestrial Hot Spring Crenarchaeota (THSC) (Takai and Sako 1999; Kato et al. 2011), whereas sequences of phylotypes A11 to A13 were affiliated with Crenarchaeota sequences retrieved from acidic hot springs of YNP. Sequences of the rest phylotypes (A14 - A17) were affiliated with environmental Euryarchaeota sequences collected from acidic environments of YNP, Ohwakudani in Japan, and the TVG (Fig. 2).

Archaeal assemblages of bottom-dwelling communities were quite different from those of planktonic ones in that uncultured groups dominated over others (90.9\% in HS03; $67.8 \%$ in $\mathrm{HS} 04 ; 76.5 \%$ in LH02) (Table 3). Of these uncultured groups, THSC constituted a substantial proportion of libraries (81.8\% in HS03; $19.4 \%$ in HSO4; and $70.6 \%$ in LH02). Other sequences were related to clone sequences recovered from YNP and the TVG (Fig. 2 and Table 3). In addition to the uncultured archaeal groups, the majority of other bottom-dwelling members were related to C. lagunensis and constituted 4.6,29.0, and 23.5\% of the total clones in $\mathrm{HSO3}$, HSO4 and LH02, respectively. A small fraction of archaeal sequences in HS04 sediments (3.2\%) were related to Thermoplasma acidophilum (Segerer et al. 1988).

Bacterial assemblages in the LH02 water and sediment samples were very similar to each other (Fig. 2 and Table 3). Most bacterial members (100\% in water and $87.4 \%$ in sediments) were affiliated with Hydrogenobaculum acidophilum (Shima and Suzuki 1993; Stohr et al. 2001). Sequences of the other bacterial clones in the LH02 sediments were related to uncultured bacteria obtained from sub-seafloor sediment (JN230291) and a hot spring in the TVG (DQ145971).

\section{DISCUSSION}

\subsection{Segregation of Archaeal Assemblages in Water Columns and Bottom Sediments}

Our molecular analyses indicated that microbial communities residing in the high-temperature sulfur-rich ponds of the TVG were simply structured. Archaea were present in all samples, whereas bacteria were detected only in LH02. Based on the phylotypes and sequence identities obtained from the clone libraries, Crenarchaeota including Caldisphaerales, Sulfolobales, and Thermoproteales and uncultivated THSC appeared to constitute a significant proportion of archaeal communities in all samples (Table 2). To establish whether any community pattern existed, cluster analyses of archaeal community assemblages using the UniFrac program (Lozupone et al. 2006) were carried out. The program calculated the genetic distance on community level from a batch of sequences recovered from different communities. The distances among each screened sequence were obtained from the 16S rDNA phylogenetic tree (Fig. 2). The analyses revealed that sediment communities tended to cluster together, whereas water communities branched off the sediment group (not shown). The pattern does not correlate with the general variation in aqueous chemistry and physical parameters among three ponds (Table 1), suggesting that factors other than those mentioned above are needed to account for the clustering of the bottom-dwelling communities from the other communities. For example, sulfate, redox potential and temperature appear to be the most prominent parameters to distinguish the HS samples from the LH sample. The segregation of archaeal assemblages in the water columns and sediments was, however, prevalent in all investigated ponds regardless of sulfate concentration, redox potential or temperature. The most plausible and apparent explanation for the clustering on community level seems to be their vertical positions in a pond.

To further elucidate whether or not archaeal assemblages were controlled by their relative vertical positions in a pond, we were prompted to infer the potential metabolisms for obtained sequences through their similarities to the sequences of known culture representatives. One feature used to distinguish the planktonic from bottom-dwelling communities is the presence of the Order Sulfolobales (including genera Sulfolubus, Sulfurisphaera and Acidianus in Fig. 2). Phylotypes with sequences affiliated with the Order Sulfolobales in the planktonic communities constituted 30 to $95 \%$ of the individual archaeal libraries (Table 3). Strains related to the Order Sulfolobales are generally thermophilic, acidophilic, and capable of acquiring metabolic energy from aerobic oxidation of elemental sulfur (Kurosawa et al. 1998; Harald and David 2006). Some strains within the Order Sulfolobales could switch between aerobic and anaerobic metabolisms (e.g., Sulfurisphaera and Acidianus). Despite the prevalent appearance of the Order Sulfolobales in the planktonic communities, phylotypes with sequences resembling $V$. distributa and $C$. lagunensis were also found. Both of these two affiliated strains are acidophilic, thermophilic microbes capable of reducing elemental sulfur and thiosulfate with the oxidation of organic carbon. $V$. distributa exhibits a weak growth under low oxygen conditions $(<2 \%$ $\mathrm{O}_{2}$ in the headspace), whereas C. lagunensis is an obligate anaerobe (Itoh et al. 2002, 2003). For comparison, members affiliated with the Order Sulfolobales and Vulcanisaeta spp. were either completely absent or reduced to a small proportion in the bottom-dwelling communities (Table 3). Instead, the proportion of sequences related to obligate anaerobes, C. lagunensis-related strains, increased up to $30 \%$ of the archaeal clones in the individual libraries. The opposite variation in the proportions of the Order Sulfolobales and Caldisphaera in the planktonic and bottom-dwelling communities suggests that the oxygen affinity plays a pivotal role in regulating the community assemblages.

Although the concentrations of dissolved oxygen in the bottom water were $26-29 \mu \mathrm{M}$, the predominance of potential obligate anaerobes in sediments makes it reasonable to speculate that the pore space of sediments would likely contain trace amounts of dissolved oxygen or become even 
anoxic. In this regard, as the dissolved oxygen is limited or completely excluded in sediments, the growth and activity of aerobes would be substantially inhibited. In contrast, opportunistic facultative or obligate anaerobes would be favored to colonize the surface of sediments where elemental sulfur is abundant and could provide metabolic energy for sulfur-respiring metabolisms under anoxic conditions. It is certain that dissolved oxygen content in water column or pore water would fluctuate through time, depending on the local precipitation and freshwater intrusion. That heterogeneously distributed micro-niches associated with sediment particulates would provide additional shielding to the oxygen stress imposed from the atmosphere further enhances the sustainability for facultative or obligate anaerobes in sediments.

While archaeal assemblages were evidently segregated between water columns and bottom sediments, bacteria were neither present in the HS ponds nor compartmentalized into distinct assemblages within LH02. Sequences of the predominant bacterial phylotype in water and sediments were closely affiliated with Hydrogenobaculum acidophilum, a strain known to grow between 40 and $75^{\circ} \mathrm{C}$ and between pH 2 and 6 by oxidizing hydrogen or elemental sulfur under an atmosphere of $1-30 \% \mathrm{O}_{2}$ (Shima and Suzuki 1993; Eder and Huber 2002). The flexibility of oxygen requirement possessed by Hydrogenobaculum spp. renders these members advantageous over others in adaption to fluctuated oxygen levels associated with different compartments in highly dynamic geothermal environments (Shima and Suzuki 1993; Macur et al. 2004; D'Imperio et al. 2008; Burgess et al. 2012).

The lack of bacteria in HS is not unusual for hot springs elsewhere [e.g., the Lassen Volcanic National Park (Siering et al. 2006)]. Potential factors leading to the detection of skewed community compositions include primer bias, extremely low $\mathrm{pH}(\leq 2.2)$, and enhanced temperature $\left(>80^{\circ} \mathrm{C}\right)$. Without rigorous tests on primer specificity and systematic sampling of fluids with various characteristics, current data do not allow for the identification of factors controlling the presence or absence of bacteria.

\subsection{Reducing Capacity of Fluids}

The concentrations of dissolved oxygen in the water columns ranged from 25 to $35 \mu \mathrm{M}$. While no systematic variation was observed in $\mathrm{HS} 03$, a decrease from 35 to $25 \mu \mathrm{M}$ with depth occurred in LH02 (Table 2). The coexistence of dissolved oxygen with sulfide has been commonly observed in YNP (Inskeep and McDermott 2005; Nordstrom et al. 2005; Spear et al. 2005), suggesting that geochemical contexts of hot fluid did not reach a redox equilibrium. That is to say, the reaction is perhaps not rapid to completely consume dissolved oxygen by sulfide. To further explore the capacity of reducing power in hot ponds, we calculated the concentrations of dissolved oxygen in equilibrium with atmospheric oxygen using the Henry's Law constants (Andrews and Wilson 1987) at the in situ temperatures. The calculation was based on the assumption that given sufficient time or probable agitation, oxygen would be partitioned into gas and aqueous phases in accordance with a specific ratio at a specific temperature. The calculation yielded equilibrium concentrations ranging from 141 to $147 \mu \mathrm{M}$ for HS03 and around $112 \mu \mathrm{M}$ for LH02. Such a range of equilibrium concentrations (112 to $147 \mu \mathrm{M}$ ) was greater than those measured ( 25 to $35 \mu \mathrm{M}$ ), suggesting the presence of oxygen consumption by either abiotic or biotic processes.

Oxygen fluxes exchanged from the atmosphere into aqueous phase could be estimated using the gas exchange coefficient and the concentration difference between gas and aqueous phases through the following formula (Kremer et al. 2003):

Flux $J=K \times S D$

$S D=0.209 \times\left(C_{e q}-C_{\text {measured }}\right) C_{e q}^{-1}$

where $K$ is the gas exchange coefficient, $S D$ represents the saturation deficiency, $C_{e q}$ is the saturated equilibrium concentration at the in situ temperature, $C_{\text {measured }}$ is the measured concentration, and the constant of 0.209 is the partial pressure of atmospheric oxygen. The exchange coefficients at $25^{\circ} \mathrm{C}$ ranged from 1.56 to $7.81 \times 10^{-2} \mathrm{~mol} \mathrm{O}_{2} \mathrm{~m}^{-2} \mathrm{~h}^{-1} \mathrm{~atm}^{-1}$, depending on the wind speed (Kremer et al. 2003). At a higher temperature, the viscosity of water film and diffusion coefficient at the air-water interface would be reduced and enhanced, respectively. Therefore, the turbulent flow as well as the molecular transport driven by the concentration gradient would increase the mass transport at the interface (Jähne and Haußecker 1998). Previous experimental data show that the exchange coefficient would be enhanced by a factor of $\sim 5$ between 25 and $52^{\circ} \mathrm{C}$ or $\sim 10$ between 25 and $92^{\circ} \mathrm{C}$ (Lau et al. 2004). To provide a conservative estimate (using a factor of 5 for $52^{\circ} \mathrm{C}$ ), the exchange coefficients ranging from 7.8 to $39.1 \times 10^{-2} \mathrm{~mol} \mathrm{O}_{2} \mathrm{~m}^{-2} \mathrm{~h}^{-1} \mathrm{~atm}^{-1}$ were used. The differences between the top dissolved and the calculated equilibrium concentrations were $117.5 \mu \mathrm{M}$ for $\mathrm{HS} 03$ and $76.7 \mu \mathrm{M}$ for LH02. Using these parameters, oxygen fluxes from the atmosphere to water column would range from 1.3 to $6.5 \times$ $10^{-2} \mathrm{~mol} \mathrm{O}_{2} \mathrm{~m}^{-2} \mathrm{~h}^{-1}$ for $\mathrm{HS} 03$, and from 1.1 to $5.6 \times 10^{-2} \mathrm{~mol}$ $\mathrm{O}_{2} \mathrm{~m}^{-2} \mathrm{~h}^{-1}$ for LH02. These oxygen fluxes could be further translated to the fluxes of reducing power with a factor of 0.5 to 4 through the stoichiometric ratios of the oxidation reactions (depending on the designated compounds: 4 for $\mathrm{Fe}^{2+}$ oxidation; 2 for $\mathrm{H}_{2}$ and $\mathrm{As}^{3+}$ oxidation; 0.67 for $\mathrm{S}^{0}$ oxidation; 0.5 for $\mathrm{H}_{2} \mathrm{~S}$ and $\mathrm{CH}_{4}$ oxidation).

Because the atmosphere is an infinitely large reservoir, the supply of oxygen to the water column is unlimited. If the observed dissolved oxygen is maintained at a constant 
level, the estimated oxygen fluxes could be converted into the consumption rate of oxygen within the pond. Using the depth of investigated ponds, the consumption rate of oxygen was calculated to range from 11 to $57 \mu \mathrm{M} \mathrm{h}^{-1}$ for HS03 and from 19 to $93 \mu \mathrm{M} \mathrm{h}^{-1}$ for LH02. Potential sources for oxygen consumption include $\mathrm{Fe}^{2+}, \mathrm{H}_{2}, \mathrm{As}^{3+}, \mathrm{S}^{0}, \mathrm{H}_{2} \mathrm{~S}$ and $\mathrm{CH}_{4}$. The low $\mathrm{pH}$ and 63 to $89^{\circ} \mathrm{C}$ of fluids reported in this study, however, render the abiotic oxidation of $\mathrm{Fe}^{2+}, \mathrm{H}_{2}, \mathrm{As}^{3+}, \mathrm{S}^{0}$ and $\mathrm{CH}_{4}$ less likely or slowly. In addition, the rates of abiotic sulfide oxidation were calculated to range from $\sim 3.4 \mu \mathrm{M} \mathrm{h}^{-1}$ for HS03 to $\sim 0.4 \mu \mathrm{M} \mathrm{h}^{-1}$ for LH02 using the experimentally derived rate constant (Millero et al. 1987) and in situ conditions. Such a range of abiotic sulfide oxidation rates accounted for $12-62 \%$ and $0.8-4 \%$ of oxygen fluxes for $\mathrm{HSO} 3$ and LH02, respectively. The rate estimates, together with the predominance of Sulfolobus spp. and Acidianus spp. in water, suggest that microbial processes mediate the consumption of a large fraction of dissolved oxygen within the water column.

\subsection{Implications for Sampling Strategy}

The community assemblages observed in this study share great similarities with those in Lassen Volcanic National Park of USA (Siering et al. 2006). In Siering et al. (2006), Sulfolobus related sequences constituted a larger proportion of archaeal communities in the springs (Devil's Kitchen 12 and Upper Sulfur Works 5), whereas Caldisphaera and THSC related sequences were found primarily in the muddy pot (Sulfur Works 5). Although the community structures and corresponding habitats are comparable with those reported in this study, no analysis of both water and sediments from a single pond or spring has been performed by Siering et al. (2006). We speculate that the segregation of archaeal communities in water columns and sediments might be a common feature in terrestrial hot ponds where the exposure to atmospheric oxygen at the air-fluid interface and the input of reduced compounds from the bottom renders a strong redox gradient. Therefore, samples recovered from either water or sediments would only represent partial community structures. Given that the functionally distinct community assemblages would be regulated strongly by the stratified redox states within a pond or between water and sediments, a thorough survey in aqueous and gas geochemistry along a vertical profile prior to molecular or microbiological analyses is recommended. With the geochemical data, the positions where the redox state changes substantially could be first determined to provide an assessment on the samples which might be critical for biological analyses.

\section{CONCLUSIONS}

We combined geochemical and molecular results to reveal that archaeal communities were evidently segregated into distinct horizons that received atmospheric oxygen at various degrees. The pattern of microbial distribution is consistent with general configuration of geochemical variations in geothermal ponds. Microorganisms with higher oxygen affinity tend to thrive near the interface between the atmosphere and water, whereas microorganisms with lower oxygen affinity preferentially proliferate in pore space within sediments where oxygen transport is more strenuous and dissolved sulfide is more abundant. Our estimates revealed that the microbial capacity for sulfide oxidation in the investigated ponds could account for 38 to $99 \%$ of the total oxygen consumption. Finally, representative community assemblages and diversities associated with geothermal ponds could be recovered only with cautious sampling which could be built on the basis of fine scaled geochemical assessment along a vertical profile.

Acknowledgements $\mathrm{We}$ are grateful to Jia-Jin $\mathrm{Wu}$ and Kuan-Chiao Chen for their assistance in field sampling and coordination of logistic supply, the Yanmingshan National Park for guiding the appropriate sampling sites, Dr. Fei-Jan Lin of the Institute of Oceanography of National Taiwan University for his technical assistance on the analyses of anions, and the Genome Research Center of National YangMing University for the technical assistance in sequencing 16S rRNA genes. We also thank Yu-Chang Chan of the Institute of Earth Sciences, Academia Sinica for providing the digital topographic map. We acknowledge the support of the National Science Council to LHL and PLW.

\section{REFERENCES}

Andrews, J. N. and G. B. Wilson, 1987: The composition of dissolved gases in deep groundwaters and groundwater degassing. In: Fritz, P. and S. K. Frape (Eds.), Saline Water and Gases in Crystalline Rocks, Geological Association Canada Special Papers, Newfoundland, 245252.

Ashelford, K. E., N. A. Chuzhanova, J. C. Fry, A. J. Jones, and A. J. Weightman, 2005: At least 1 in 20 16S rRNA sequence records currently held in public repositories is estimated to contain substantial anomalies. Appl. Environ. Microbiol., 71, 7724-7736, doi: 10.1128/AEM. 71.12.7724-7736.2005. [Link]

Burgess, E. A., J. M. Unrine, G. L. Mills, C. S. Romanek, and J. Wiegel, 2012: Comparative geochemical and microbiological characterization of two thermal pools in the Uzon Caldera, Kamchatka, Russia. Microb. Ecol., 63, 471-489, doi: 10.1007/s00248-011-9979-4. [Link]

Chen, C. H. and Y. J. Wu, 1971: Volcanic geology of the Tatun geothermal area, northern Taiwan. Proc. Geol. Soc. China, 14, 5-20.

Clesceri, L. S., A. E. Greenberg, and A. D. Eaton, 1998: Standard Methods for the Examination of Water and 
Wastewater. American Public Health Association, Washington, DC, $1325 \mathrm{pp}$.

Cline, J. D., 1969: Spectrophotometric determination of hydrogen sulfide in natural waters. Limnol. Oceanogr., 14, 454-458, doi: 10.4319/lo.1969.14.3.0454. [Link]

Costa, K. C., J. B. Navarro, E. L. Shock, C. L. Zhang, D. Soukup, and B. P. Hedlund, 2009: Microbiology and geochemistry of great boiling and mud hot springs in the United States Great Basin. Extremophiles, 13, 447459, doi: 10.1007/s00792-009-0230-x. [Link]

Cox, A., E. L. Shock, and J. R. Havig, 2011: The transition to microbial photosynthesis in hot spring ecosystems. Chem. Geol., 280, 344-351, doi: 10.1016/j.chemgeo. 2010.11.022. [Link]

D’Imperio, S., C. R. Lehr, H. Oduro, G. Druschel, M. Kühl, and T. R. McDermott, 2008: Relative importance of $\mathrm{H}_{2}$ and $\mathrm{H}_{2} \mathrm{~S}$ as energy sources for primary production in geothermal springs. Appl. Environ. Microbiol., 74, 5802-5808, doi: 10.1128/aem.00852-08. [Link]

DeLong, E. F., L. T. Taylor, T. L. Marsh, and C. M. Preston, 1999: Visualization and enumeration of marine planktonic archaea and bacteria by using polyribonucleotide probes and fluorescent in situ hybridization. Appl. Environ. Microbiol., 65, 5554-5563.

DeSantis, T. Z., Jr., P. Hugenholtz, K. Keller, E. L. Brodie, N. Larsen, Y. M. Piceno, R. Phan, and G. L. Andersen, 2006: NAST: A multiple sequence alignment server for comparative analysis of 16S rRNA genes. Nucleic Acids Res., 34, W394-W399, doi: 10.1093/nar/gkl244. [Link]

Eder, W. and R. Huber, 2002: New isolates and physiological properties of the Aquificales and description of Thermocrinis albus sp. nov. Extremophiles, 6, 309318, doi: 10.1007/s00792-001-0259-y. [Link]

Eder, W., W. Ludwig, and R. Huber, 1999: Novel 16S rRNA gene sequences retrieved from highly saline brine sediments of Kebrit Deep, Red Sea. Arch. Microbiol., 172, 213-218, doi: 10.1007/s002030050762. [Link]

Harald, H. and P. David, 2006: Sulfolobales. In: Falkow, M. D. S., E. Rosenberg, K.-H. Schlelfer, and E. Stackebandt (Eds.), The Prokaryotes, Springer, New York, 23-51.

Huber, G. and K. O. Stetter, 1991: Sulfolobus metallicus, sp. nov., a novel strictly chemolithoautotrophic thermophilic archaeal species of metal-mobilizers. Syst. Appl. Microbiol., 14, 372-378, doi: 10.1016/S0723-20 20(11)80312-7. [Link]

Inskeep, W. P., and T. R. McDermott, 2005: Geomicrobiology of acid-sulfate-chloride springs in Yellowstone National Park. In: Inskeep, W. P. and T. R. McDermott (Eds.), Geothermal Biology and Geochemistry in Yellowstone National Park, Montana State University, Bozeman, 143-162.

Itoh, T., K. Suzuki, and T. Nakase, 2002: Vulcanisaeta dis- tributa gen. nov., sp. nov., and Vulcanisaeta souniana sp. nov., novel hyperthermophilic, rod-shaped crenarchaeotes isolated from hot springs in Japan. Int. J. Syst. Evol. Microbiol., 52, 1097-1104, doi: 10.1099/ ijs.0.02152-0. [Link]

Itoh, T., K. Suzuki, P. C. Sanchez, and T. Nakase, 2003: Caldisphaera lagunensis gen. nov., sp. nov., a novel thermoacidophilic crenarchaeote isolated from a hot spring at Mt Maquiling, Philippines. Int. J. Syst. Evol. Microbiol., 53, 1149-1154, doi: 10.1099/ijs.0.02580-0. [Link]

Jähne, B. and H. Haußecker, 1998: Air-water gas exchange. Annu. Rev. Fluid Mech., 30, 443-468, doi: 10.1146/annurev.fluid.30.1.443. [Link]

Kato, S., T. Itoh, and A. Yamagishi, 2011: Archaeal diversity in a terrestrial acidic spring field revealed by a novel PCR primer targeting archaeal 16S rRNA genes. FEMS Microbiol. Lett., 319, 34-43, doi: 10.1111/j.1574-69 68.2011.02267.x. [Link]

Kremer, J. N., A. Reischauer, and C. D’Avanzo, 2003: Estuary-specific variation in the air-water gas exchange coefficient for oxygen. Estuaries, 26, 829-836, doi: 10. 1007/BF02803341. [Link]

Kurosawa, N., Y. H. Itoh, T. Iwai, A. Sugai, I. Uda, N. Kimura, T. Horiuchi, and T. Itoh, 1998: Sulfurisphaera ohwakuensis gen. nov., sp. nov., a novel extremely thermophilic acidophile of the order Sulfolobales. Int. J. Syst. Evol. Microbiol., 48, 451-456, doi: 10.10 99/00207713-48-2-451. [Link]

Lane, D. J., 1991: 16S/23S rRNA sequencing. In: Stackebrandt, E. and M. Goodfellow (Eds.), Nucleic Acid Techniques in Bacterial Systematics, John Wiley \& Sons, Chichester, 115-175.

Lau, R., W. Peng, L. G. Velazquez-Vargas, G. Q. Yang, and L.-S. Fan, 2004: Gas-liquid mass transfer in highpressure bubble columns. Ind. Eng. Chem. Res., 43, 1302-1311, doi: 10.1021/ie030416w. [Link]

Lee, H. F., T. F. Yang, T. F. Lan, S. R. Song, and S. Tsao, 2005: Fumarolic gas composition of the Tatun Volcano Group, northern Taiwan. Terr. Atmos. Ocean. Sci., 16, 843-864.

Lozupone, C., M. Hamady, and R. Knight, 2006: UniFrac - An online tool for comparing microbial community diversity in a phylogenetic context. BMC Bioinformatics, 7, 371-384, doi: 10.1186/1471-2105-7-371. [Link]

Macur, R.E., H. W. Langner, B. D. Kocar, and W.P.Inskeep, 2004: Linking geochemical processes with microbial community analysis: Successional dynamics in an arsenic-rich, acid-sulphate-chloride geothermal spring. Geobiology, 2, 163-177, doi: 10.1111/j.1472-4677.20 04.00032.x. [Link]

Maidak, B. L., J. R. Cole, T. G. Lilburn, C. T. Parker, Jr., P. R. Saxman, R. J. Farris, G. M. Garrity, G. J. Olsen, T. M. Schmidt, and J. M. Tiedje, 2001: The RDP-II 
(ribosomal database project). Nucleic Acids Res., 29, 173-174, doi: 10.1093/nar/29.1.173. [Link]

Meyer-Dombard, D. R., E. L. Shock, and J. P. Amend, 2005: Archaeal and bacterial communities in geochemically diverse hot springs of Yellowstone National Park, USA. Geobiology, 3, 211-227, doi: 10.1111/j.1472-46 69.2005.00052.x. [Link]

Millero, F. J., S. Hubinger, M. Fernandez, and S. Garnett, 1987: Oxidation of $\mathrm{H}_{2} \mathrm{~S}$ in seawater as a function of temperature, $\mathrm{pH}$, and ionic strength. Environ. Sci. Technol., 21, 439-443, doi: 10.1021/es00159a003. [Link]

Nordstrom, D. K., J. W. Ball, and R. B. McCleskey, 2005: Ground water to surface water: Chemistry of thermal outflows in Yellowstone National Park. In: Inskeep, W. P. and T. R. McDermott (Eds.), Geothermal Biology and Geochemistry in Yellowstone National Park, Montana State University, Bozeman, 73-94.

Perevalova, A. A., T. V. Kolganova, N.-K. Birkeland, C. Schleper, E. A. Bonch-Osmolovskaya, and A. V. Lebedinsky, 2008: Distribution of Crenarchaeota representatives in terrestrial hot springs of Russia and Iceland. Appl. Environ. Microbiol., 74, 7620-7628, doi: 10.1128/AEM.00972-08. [Link]

Saitou, N. and M. Nei, 1987: The neighbor-joining method: A new method for reconstructing phylogenetic trees. Mol. Biol. Evol., 4, 406-425.

Segerer, A., A. Neuner, J. K. Kristjansson, and K. O. Stetter, 1986: Acidianus infernus gen. nov., sp. nov., and Acidianus brierleyi comb. nov.: Facultatively aerobic, extremely acidophilic thermophilic sulfur-metabolizing archaebacteria. Int. J. Syst. Evol. Microbiol., 36, 559564, doi: 10.1099/00207713-36-4-559. [Link]

Segerer, A., T. A. Langworthy, and K. O. Stetter, 1988: Thermoplasma acidophilum and Thermoplasma volcanium sp. nov. from solfatara fields. Syst. Appl. Microbiol., 10, 161-171, doi: 10.1016/S0723-2020(88)800 31-6. [Link]

Shima, S. and K.-I. Suzuki, 1993: Hydrogenobacter acidophilus sp. nov., a thermoacidophilic, aerobic, hydrogen-oxidizing bacterium requiring elemental sulfur for growth. Int. J. Syst. Evol. Microbiol., 43, 703-708, doi: 10.1099/00207713-43-4-703. [Link]

Shock, E. L., M. Holland, D. Meyer-Dombard, and J. P. Amend, 2005: Geochemical sources of energy for microbial metabolism in hydrothermal ecosystems: Obsidian Pool, Yellowstone National Park. In: Inskeep, W. P. and T. R. McDermott (Eds.), Geothermal Biol- ogy and Geochemistry in Yellowstone National Park, Montana State University, Bozeman, 95-112.

Siering, P. L., J. M. Clarke, and M. S. Wilson, 2006: Geochemical and biological diversity of acidic, hot springs in Lassen Volcanic National Park. Geomicrobiol.J., 23, 129-141, doi: 10.1080/01490450500533916. [Link]

Song, S. R., S. Tsao, and H. J. Lo, 2000: Characteristics of the Tatun volcanic eruptions, north Taiwan: implications for a cauldron formation and volcanic evolution. Proc. Geol. Soc. China, 43, 361-378.

Spear, J. R., J. J. Walker, T. M. McCollom, and N. R. Pace, 2005: Hydrogen and bioenergetics in the Yellowstone geothermal ecosystem. Proc.Natl.Acad.Sci.USA, 102, 2555-2560, doi: 10.1073/pnas.0409574102. [Link]

Stohr, R., A. Waberski, H. Völker, B. J. Tindall, and M. Thomm, 2001: Hydrogenothermus marinus gen. nov., sp. nov., a novel thermophilic hydrogen-oxidizing bacterium, recognition of Calderobacterium hydrogenophilum as a member of the genus Hydrogenobacter and proposal of the reclassification of Hydrogenobacter acidophilus as Hydrogenobaculum acidophilum gen. nov., comb. nov., in the phylum 'Hydrogenobacter/ Aquifex’. Int. J. Syst. Evol. Microbiol., 51, 1853-1862, doi: 10.1099/00207713-51-5-1853. [Link]

Suzuki, T., T. Iwasaki, T. Uzawa, K. Hara, N. Nemoto, T. Kon, T. Ueki, A. Yamagishi, and T. Oshima, 2002: Sulfolobus tokodaii sp. nov. (f. Sulfolobus sp. strain 7), a new member of the genus Sulfolobus isolated from Beppu Hot Springs, Japan. Extremophiles, 6, 39-44, doi: 10.1007/s007920100221. [Link]

Takai, K. and Y. Sako, 1999: A molecular view of archaeal diversity in marine and terrestrial hot water environments. FEMS Microbiol. Ecol., 28, 177-188, doi: 10. 1111/j.1574-6941.1999.tb00573.x. [Link]

Tamura, K., M. Nei, and S. Kumar, 2004: Prospects for inferring very large phylogenies by using the neighbor-joining method. Proc. Natl. Acad. Sci. USA, 101, 11030-11035, doi: 10.1073/pnas.0404206101. [Link]

Tamura, K., J. Dudley, M. Nei, and S. Kumar, 2007: MEGA4: Molecular evolutionary genetics analysis (MEGA) software version 4.0. Mol. Biol. Evol., 24, 1596-1599, doi: 10.1093/molbev/msm092. [Link]

Wang, K. L., S. L. Chung, C. H. Chen, R. Shinjo, T. F. Yang, and C. H. Chen, 1999: Post-collisional magmatism around northern Taiwan and its relation with opening of the Okinawa Trough. Tectonophysics, 308, 363-376, doi: 10.1016/S0040-1951(99)00111-0. [Link] 